\title{
Empirical Research on the Source of Tourism Economic Growth in China-Based on the Perspective of Productivity
}

\author{
Wu Linping \\ Minjiang University \\ Fuzhou, Fujian 350108
}

\begin{abstract}
In order to explore the driving factors of Chinese tourism economic growth, this paper measures the total factor productivity of Chinese tourism industry from 1995 to 2015 by means of the Solow residual method, and discusses the fluctuation relationship of total factor productivity and single factor productivity on tourism economic growth, and also analyzes the contribution of total factor productivity and production factor to the tourism economic growth. The findings show that the total factor productivity in Chinese tourism industry is relatively low from 1995 to 2015 , and the contribution of total factor productivity to tourism economic growth is not high, while the contribution of capital to the tourism economic growth is the highest, and Chinese tourism economic growth belongs to factor-driven intensive growth mode; if total factor productivity is low, excessive capital inputs will decrease the tourism economic growth rate on the contrary; the deepening of capital weakens the impact of labor factor growth on tourism output, on the other hand, it greatly reduces the capital productivity which has led to the decline of the growth of tourism output.
\end{abstract}

Keywords-Tourism economic growth; total factor productivity; single factor productivity; Solow residual method; economic growth contribution

\section{INTRODUCTION}

Under the guidance of Deng Xiaoping "Mount Huang Speech" in 1979, China's tourism industry which has huge resource advantage and the demand inventory accumulated in the international market for several years, has continued to develop rapidly for more than 20 years and has become an important industry in the national economy of our country. Except for special years (such as the influence of SARS in 2003) before 2006, the tourism economy of our country kept a high-speed growth above $10 \%$ per year, and from 1996 to 2005 , the tourism economic growth rate was averagely $12.85 \%$, and after 2006, the growth speed was slightly decreased, and from 2006 to 2015, the average growth speed was $6.12 \%$. However, what are the reasons behind the tourism economic growth? It is very important to study the source of tourism economic growth both in theory and in practice. Currently, the most opinions for the research about the economic growth in China hold that, the economic growth in China is mainly driven by capital, land, labor force and other production factor input, while the contribution of productivity (TFP) to economic growth is relatively low, and the main problem that shall be urgently solved is the transformation of the model of economic growth [1]. Up till present, there are few researches about the influence of tourism economic growth in China, Zuo Bing (2008) held that, Chinese tourism industry belonged to typical (labor) factor-driven growth mode, and the contribution of labor input to economic growth reached up to $63.69 \%$, the capital contribution rate was $11.86 \%$, the contribution rate of total factor productivity was $24.45 \%$ [2], but in 2011, another research of Zuo Bing indicated that, the tourism economic growth of our country mainly relied on factor input, rather than the pursuit for technical progress, of which the degree of influence for capital and resource endowment is the biggest [3]. However, these two articles failed to deeply dig out the internal source of tourism economic growth, and the research was relatively early, and the data used therein were before 2008 . This research adopts the data of tourism industry for our country from 1995 to 2015, to further conduct in-depth research about the influencing factors and internal functional mechanism of tourism economic growth in our country.

\section{RESEARCH METHOD}

In the research, the measurement method for total factor productivity is Solow residual method, and when being compared with the stochastic frontier production function method and DEA data envelope method, Solow residual method has clear significance of economics, and can comprehensively consider the influence and contribution of various input factors on output [4], and in Solow residual value, total factor productivity is regarded as residual, Cobb-Douglas production function is regarded as the basis, and the least square method regression is adopted, under the condition of assuming constant returns to scale, it is applicable to obtain the elastic coefficient for the output of input factor, and through conducting $t$ differential calculus for the two sides of the function, it is applicable to calculate the contribution rate of various production factors and total factor productivity for the tourism output. 
A. Research method and model

1) Total factor productivity and tourism economy contribution calculation method

This paper uses Cobb-Douglas production function as the basis, and assumes that the formation of tourism economic output is mainly caused by the input of two production factors, including labor (L) and capital (K), and the marginal yield of factors will be decreased with the increase in the using quantity of factors, and the general production function is $\mathrm{Y}=\mathrm{F}(\mathrm{K}, \mathrm{L})$, and the specific functional form is as follows:

$$
Y=A K^{\alpha} L^{\beta} e^{\mu}
$$

Of which, $\mathrm{A}$ is the efficient, $\alpha$ and $\beta$ respectively represent the output elasticity of capital and labor input in the tourism industry; $\mathrm{Y}$ represents the output of tourism industry, $\mathrm{K}$ represents the physical capital stock for the input in the tourism industry, and $\mathrm{L}$ represents the total employees of the tourism industry.

In Formula (1), take the logarithm of the two sides, and rewrite as follows

$$
\ln (Y)=\ln (A)+\alpha \ln (K)+\beta \ln (L)+\mu
$$

Assuming constant returns to scale, i.e., the technical progress is Hicks neutral, $\beta=1-\alpha$, and the function can be expressed as follows:

$$
\ln (Y)=\ln (A)+\alpha \ln (K)+(1-\alpha) \ln (L)+\mu
$$

It can be converted as:

$$
\ln \left(\frac{Y}{L}\right)=\ln (A)+\alpha \ln \left(\frac{K}{L}\right)+\mu
$$

Use the least square method regression to get the aforementioned parameters of $\alpha$ and $\beta$; after that, it is applicable to use the following formula, to get the total factor productivity of tourism industry:

$$
T F P=\frac{Y}{K^{\alpha} L^{(1-\alpha)}}
$$

As for the calculation of tourism total factor productivity and input factors, it is applicable to refer to Jorgenson growth model theory, and after conducting time $t$ differential calculus for the two sides of Function $\mathrm{Y}=\mathrm{F}(\mathrm{K}, \mathrm{L})$, divide it by $\mathrm{Y}$, and then collect it as follows:

$$
\frac{\dot{Y}}{Y}=\frac{\dot{A}}{A}+\alpha \frac{\dot{K}}{K}+(1-\alpha) \frac{\dot{L}}{L}
$$

Of which $\frac{\dot{Y}}{Y}, \frac{\dot{A}}{A}, \frac{\dot{K}}{K}$ and $\frac{\dot{L}}{L}$ respectively represent the growth rate of $\mathrm{Y}, \mathrm{A}, \mathrm{K}$ and $\mathrm{L}$.

As per Formula 6, the growth formula of tourism output can be simplified as the following formula:

$$
Y g=T F P g+\alpha K g+(1-\alpha) L g
$$
$\dot{A}$
$\frac{\dot{K}}{A}, \quad \frac{\dot{K}}{K}$ and $\frac{\dot{L}}{L}$.

As per the aforementioned formula, the contribution rate of total factor productivity, capital and labor input for the tourism economic growth is respectively $\mathrm{TFPg} / \mathrm{Yg}, \alpha \mathrm{Kg} / \mathrm{Yg}$ and $(1-\alpha) \mathrm{Lg} / \mathrm{Yg}$.

\section{2) Data source and processing}

In consideration of data accessibility, this paper selects the tourism enterprises included into Chinese Tourism Statistical Yearbook from 1995 to 2015 as the research sample. The labor input index of tourism industry adopts the tourism enterprise employees provided in Chinese Tourism Statistical Yearbook (Copy). industry

a) Confirmation on the output index of tourism

The output index of tourism industry is used for representing the economic development of tourism, and the growth rate is used to express the speed of tourism economic growth. This paper selects the operating incomes of tourism enterprises included into Chinese Tourism Statistical Yearbook (Copy) from 1995 to 2015 to express the tourism output, and use the tourism price index of various years (China Statistical Yearbook) to adjust the output index of tourism industry as the unchanged price in 1995. industry

b) Confirmation on the capital stock index of tourism

As for the capital stock of tourism industry, since our country has no relevant statistic data about the capital stock of tourism, through referring to the research experience of predecessors, select the net value for the fixed assets of tourism enterprises in various years to replace the capital stock of tourism. Chinese Tourism Statistic Annual (Copy) has provided the net value for the fixed assets of tourism enterprises before 2000, and it is only requested to adjust the net value for the fixed assets with the fixed asset investment price index of various years (China Statistical Yearbook) as the unchanged price in 1995. Besides, after 2000, since what Chinese Tourism Statistical Yearbook provides is the original value for the fixed assets of tourism enterprises within various years, so this paper adopts perpetual inventory method for calculation $^{[2]}$, and the estimation formula is:

$$
K_{t}=(1-\delta) K_{t-1}+I_{t} / P_{t}
$$

In the formula, $K_{t}$ indicates the capital stock of $\mathrm{t}$ year; $\delta$ indicates the rate of depreciation of capital (as per the research of Zuo Bing and BaoJigang, assuming that the annual rate of depreciation is $5 \%) ; K_{t-1}$ indicates the capital stock of the previous year; $I_{t}$ indicates the nominal fixed asset investment amount per year; $P_{t}$ is the fixed asset investment 
price index per year (regard the year of 1995 as the base period), and since the base period for the fixed asset investment price index given in China Statistical Yearbook is 1992, the base period for the fixed asset investment price index is changed to the year of 1995; assume that the fixed asset investment price index in 1995 was 1 , convert the original fixed asset investment price index into price index $P_{t}$ in the base period of 1995, and after confirming the net value for the fixed assets of tourism enterprises in 2000, it is applicable to calculate the capital stock of tourism enterprises after the year of 2000 as per Formula 8 .

\section{INFLUENCE OF FACTOR PRODUCTIVITY ON THE TOURISM ECONOMIC GROWTH}

The tourism economic growth can be influenced by the productivity of all factors, including the labor productivity, capital productivity and total factor productivity, and the first two are called as single factor productivity.

\section{A. Influence of total factor productivity on tourism economic growth}

1) Production function elasticity coefficient measurement Using the tourism output, capital and labor input data of our country from 1995 to 2015 to conduct the least square method regression for Formula 4, and the result is as shown in Table I, and as can be seen from the regression result of Table I : under the significance level of $\alpha=0.05$, the model can pass $F$ inspection, while $\mathrm{R}^{2}=0.898$, indicating that the fitting degree of the model with the actual tourism economic growth is high. Under the significance level of $\alpha=0.05$, Variable $\ln \left(\frac{K}{L}\right)$ can pass t inspection.

As can be seen in Tab.1, the elastic coefficient for the tourism output of all factors is as follows:

As for the elastic coefficient for the output of capital K, $\alpha=0.682$; as for the elastic coefficient for labor force, $\beta=1-\alpha=0.318$, indicating that the influence degree of capital input on tourism output is bigger than labor input.

TABLE I LEAST SQUARES REGRESSION RESULTS

\begin{tabular}{|c|c|c|c|c|}
\hline Variable & Coefficient & Std.Error & t-Statistic & Sig. \\
\hline (constant) & 0.319 & 0.161 & 1.980 & 0.062 \\
\hline $\operatorname{Ln}(\mathrm{K} / \mathrm{L})$ & 0.682 & 0.053 & 12.942 & 0.000 \\
\hline R-squared & 0.898 & & Sum squared resid & 0.138 \\
\hline Adjusted R-squared & 0.893 & & F-Statistic & 167.484 \\
\hline S.E. of regression & 1.213 & & Sig.( F-Statistic) & 0.000 \\
\hline
\end{tabular}

2) Analysis on the fluctuation of total factor productivity

The improvement of total factor productivity for tourism is the improvement of comprehensive utilization level of various resource factors. Put $\alpha$, tourism output index, Capital and labor force index into Formula 5, and then calculate the total factor productivity (TFP) and its growth rate of tourism industry in our country from 1995 to 2015; as for the specific calculation result, please refer to Table II and Fig.1.

TABLE II The GROWTH RATE OF TFP IN CHINA (1995-2015)

\begin{tabular}{|c|c|c|c|c|c|}
\hline Year & TFP & $\begin{array}{l}\text { TFP Growth } \\
\text { Rate }\end{array}$ & Year & TFP & TFP Growth \\
\hline 1995 & & -- & 2006 & 54.9163 & -0.0223 \\
\hline 1996 & 50.3664 & & 2007 & 59.4483 & 0.0825 \\
\hline 1997 & 59.2836 & 0.1770 & 2008 & 55.5948 & -0.0648 \\
\hline 1998 & 53.2120 & -0.1024 & 2009 & 58.6861 & 0.0556 \\
\hline 1999 & 51.5203 & -0.0318 & 2010 & 63.9916 & 0.0904 \\
\hline 2000 & 54.3361 & 0.0547 & 2011 & 61.8357 & -0.0337 \\
\hline 2001 & 56.2530 & 0.0353 & 2012 & 65.2163 & 0.0547 \\
\hline 2002 & 57.0188 & 0.0136 & 2013 & 66.4891 & 0.0195 \\
\hline 2003 & 58.5587 & 0.0270 & 2014 & 69.4560 & 0.0446 \\
\hline 2004 & 55.1890 & -0.0575 & 2015 & 71.9382 & 0.0357 \\
\hline 2005 & 57.2021 & 0.0365 & -- & -- & -- \\
\hline Average Value & -- & -- & -- & -- & 0.0198 \\
\hline
\end{tabular}




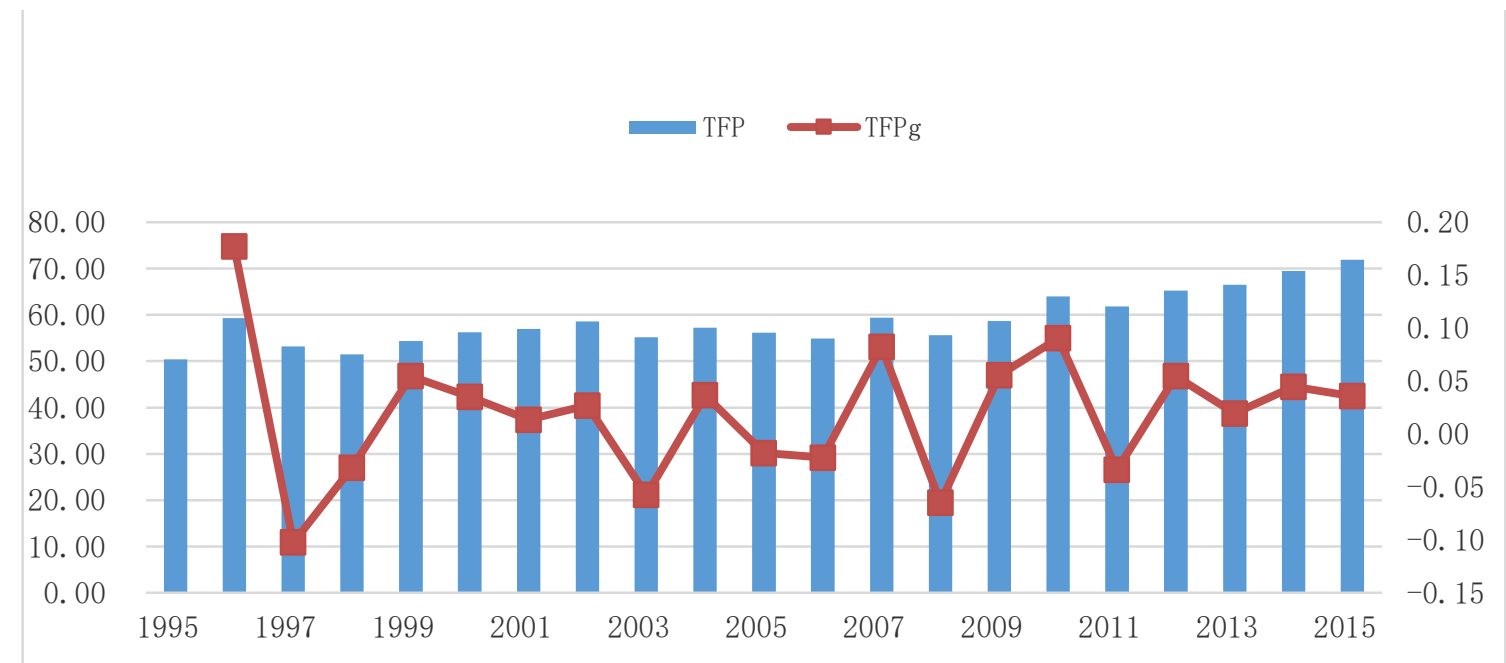

Fig. 1 The Growth Curve of TFP and TFP Growth Rate of Tourism Industry in China (1996-2012)

Total factor productivity is an important index measuring the economic growth quality, and as per Solow residual method, for enterprises, the enterprise output part that cannot explained with production factor input is generally understood as the cause of the improvement of total productivity of enterprises [4]. As can be seen in Table II and Fig.1, from 1996 to 2015, the total factor productivity growth rate of tourism industry in China were relatively low, and the average growth was merely $1.98 \%$ per year, and total factor productivity growth rates fluctuated considerably, and in the 20-year research, the total factor productivity growth of tourism in 6 years is negative, indicating that the total factor productivity rate of tourism in China was relatively low and unstable.

3) Fluctuation relationship between total factor productivity and tourism economic growth

As can be seen from Fig.2, the growth rate of output and input indexes for the tourism industry of our country presents the fluctuation mode of mutual presentation of ups and downs; before 2006, the fluctuation amplitude was relatively big, and after 2006, there was the trend of slow growth speed, of which the changing trend for the growth rate of total factor productivity and the growth speed of tourism output was kept consistent as a whole, indicating that the growth of total factor productivity changes was closely related to the fluctuation of tourism economy in our country, but since the total factor Productivity for tourism throughout most years was commonly low, the overall contribution to the growth of tourism economy wasn't so big (as shown in Table III). As can be seen from Fig.2, the growth of labor force, the growth of capital, the growth of total factor productivity and the growth rules of tourism economy have shown relatively big difference. As shown in Fig.2, before 2006, the ups and downs for the growth rate of capital and the growth rate of tourism output were relatively consistent, indicating that the growth capital input during the period had promoted tourism economic growth; after 2006, the capital growth rate and tourism output presented the characteristics of collateral peaks and valleys; meanwhile, and there were the changing rules of capital growth rate in contrast to the growth of total factor productivity for tourism, indicating that after 2006, the increase in capital input failed to drive the tourism output to realize the growth of the same direction, and even generated the trend of slow economic growth speed, and this was mainly because of the excessive input of capital, which had caused factor congestion, and then finally decreased the productivity and tourism economic output, so it was unstable and unsustainable to use factor input to drive tourism economic growth. As can be seen in Fig.2, from 1996 to 2015, the tourism economic growth rate in our country had always kept a relatively big fluctuation amplitude, and as can be seen from the trend, the growth amplitude wasn't improved, but presented a trend of slight decrease. As shown in Fig.2, the labor input in tourism industry was always kept a low-speed stable growth after 1998, and the influence on the tourism economic growth and total factor productivity wasn't obvious. 


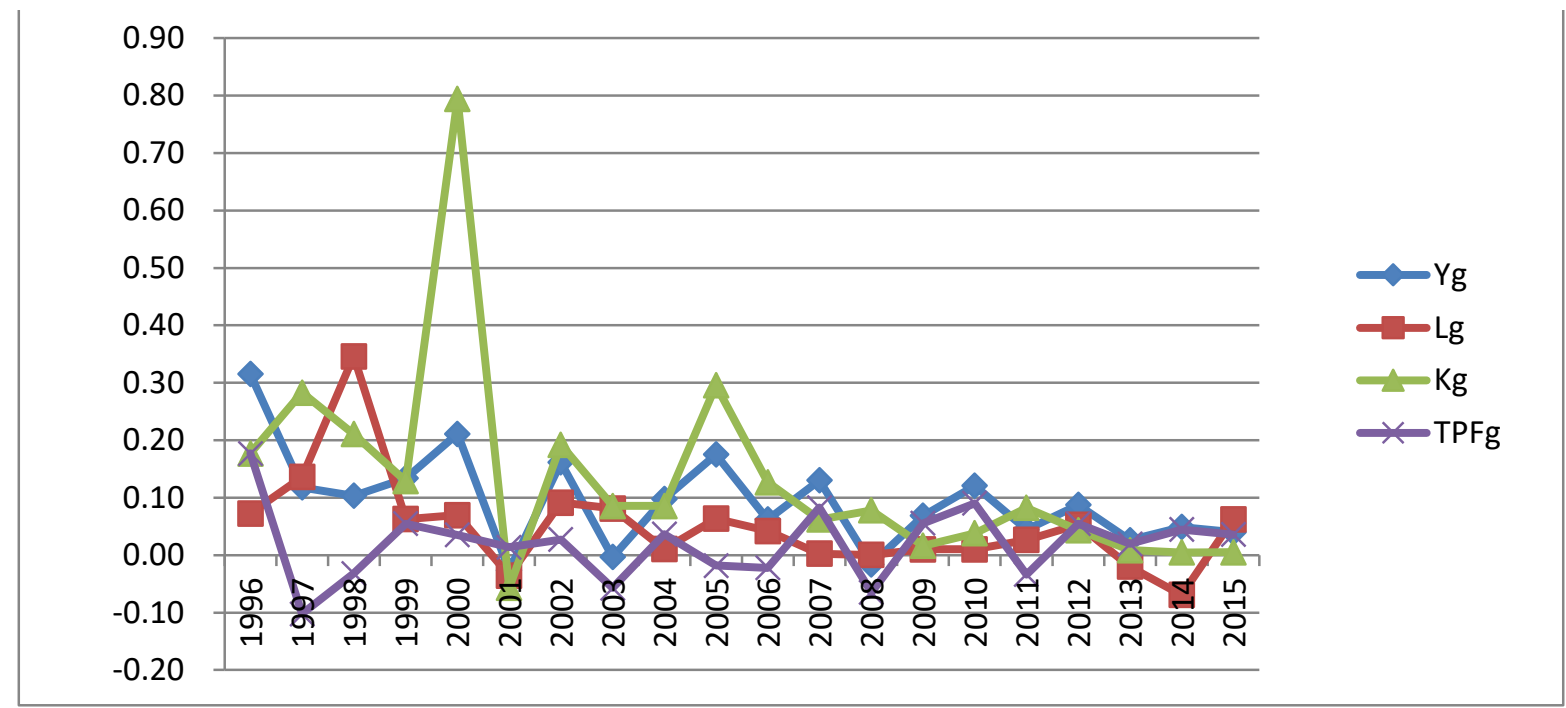

Fig. 2 The Fluctuation of the TFP Growth Rate and the Input and Output Elements (1995-2015)

\section{B. Influence of single factor productivity on tourism economic growth}

The single factor productivity can be divided into labor productivity and capital productivity, of which labor productivity can promote economic growth through improving the using efficiency of labor force in economic growth process. The labor productivity is not only the important factor influencing economic growth quantity, but also an important factor for economic growth quality [5], and labor productivity is equivalent to the tourism output divided by tourism employees, and is expressed with Y/L; capital productivity is also called capital output rate and it is equivalent to the tourism output divided by the capital, and is expressed with $\mathrm{Y} / \mathrm{K}$, and what it reflects is the using efficiency of social resources, and the improvement of capital output can exert a positive effect on the economic growth. $\mathrm{K} / \mathrm{L}$ indicates the capital-labor ratio (reflecting the capital deepening degree), and it will affect the influence of labor productivity on tourism economic growth.

The relationship between capital productivity and labor productivity can be expressed as per the following formula:

$$
\frac{Y}{K}=\frac{Y}{L} \div \frac{K}{L}
$$

As can be seen in Fig. 3, from 1995 to 2015, the labor productivity of tourism in our country $(\mathrm{Y} / \mathrm{L})$ presented a stable trend of growth during the analysis period, but the stable growth of labor productivity failed to bring the stable growth of tourism output. As can be seen in Fig.3, the index reflecting the capital deepening degree $(\mathrm{K} / \mathrm{L})$ started to constantly increase since 1995, and the growth speed was higher than the labor productivity (Y/L), and after 2003, the growth amplitude difference was further enlarged, which had largely offset the effect of labor productivity growth on tourism output growth, because the capital deepening (the growth of $\mathrm{Y} / \mathrm{K}$ is higher than the growth of $\mathrm{Y} / \mathrm{L}$ ) caused the sharp decrease in the capital investment efficiency $(\mathrm{Y} / \mathrm{K})$, and then finally caused the decrease in tourism output, and the tourism economic growth was developing towards the direction of capital replacing labor force. Thus, in order to ensure the constant growth of tourism economy in China, it is requested to firstly improve capital productivity.

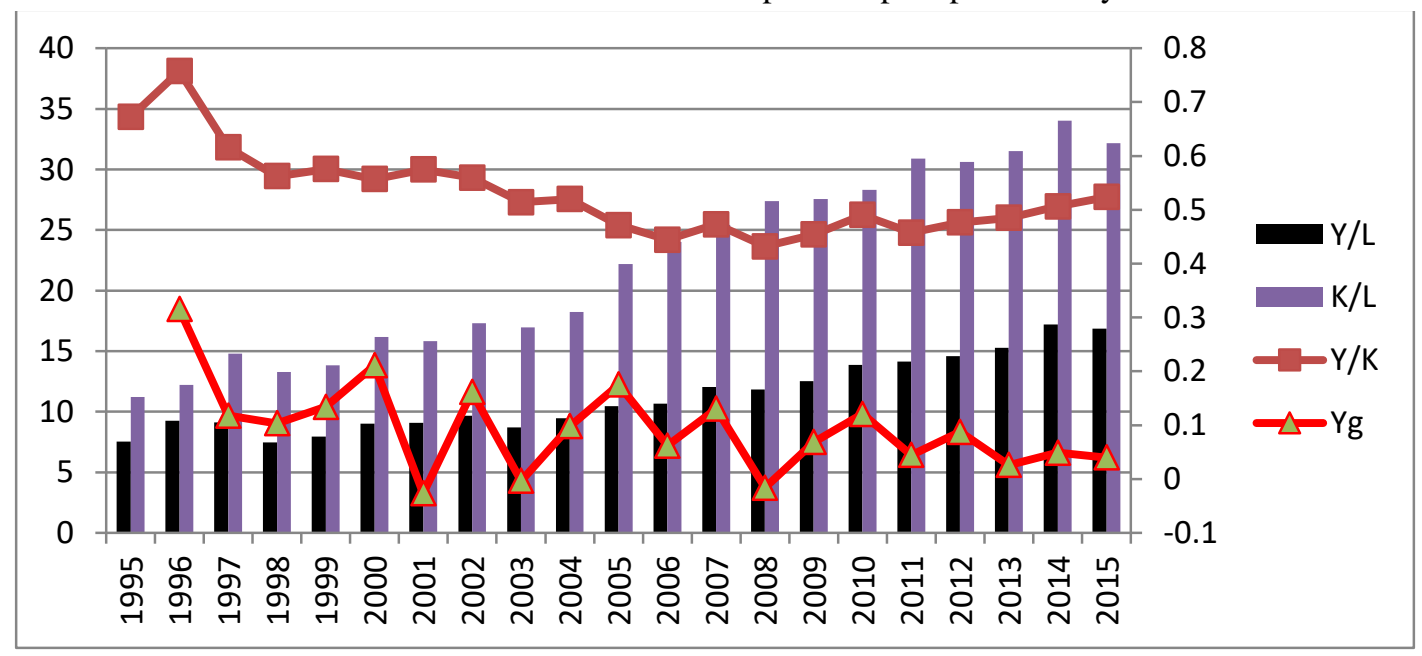

Fig. 3 The Fluctuation of Single Factor Productivity and Tourism Economic Growth (1995-2012) 


\section{CONTRIBUTION OF TOURISM TOTAL FACTOR PRODUCTIVITY AND FACTOR INPUT TO TOURISM ECONOMIC GROWTH}

As can be seen from Table III, from 1996 to 2015, the average growth of tourism incomes of our country was $9.49 \%$, and the annual average growth speed of capital and labor force was respectively $11.07 \%$ and $5.08 \%$, while the annual average growth rate of total factor productivity was merely $1.98 \%$. The contribution of production factor capital, labor and total factor productivity for tourism economic growth was respectively $62.01 \%, 17.1 \%$ and $20.89 \%$, of which $79.11 \%$ contribution limits were from the input of production factor, while the contribution of production efficiency was merely $20.89 \%$, which was lower than the value of $24.45 \%$ [2] calculated by Zou Bing et al. (2008) from 1992 to 2005, indicating that from 2005 to 2015, the total factor productivity for tourism in China didn't make any difference, and the total factor productivity was explained as "uninformed measurement", and accurately, it is the part that cannot be explained considering factor input, it not only includes the part we want (technical progress and organization innovation), but also the part we don't want (calculation error, the neglected variation influence, etc. $)^{[4]}$, thus, in reality, the contribution of total factor productivity to the growth of tourism industry should also be lower than the data, indicating that the tourism economic growth in our country is mostly driven by factor input growth, and it is a kind of externally extended growth driven by factors, rather than the quality improved growth driven by productivity, and as per the definition of Wei Jie et al., it is held that the economic growth with the productivity contribution rate exceeding $50 \%$ belongs to intensive growth mode [5], as per the standard, the tourism economy of our country belongs to typical intensive growth mode. In the factor contribution, the contribution of capital factor to tourism economic growth reached up to $62.01 \%$, while the contribution of labor growth was merely $17.1 \%$, while the research conclusion of Zuo Bing et al. (2008) was that the contribution of labor force growth was $63.69 \%$, while the capital contribution was merely $11.86 \%$ [2], and such difference was incurred by different sample years; the sample year of Zuo Bing et al. was 1992-2005, while the sample year of the research was 1995-2015, so the output elasticity coefficient difference obtained thereby was relatively big; on the other hand, the growth speed of labor after 2005 slowed down, and the average growth rate of labor from 2006 to 2015 was merely $5.08 \%$. As can be seen in Tab.3, there was a big change in the tourism economic development of China, and then after 2003, the capital-labor ratio was bigger than the growth amplitude of labor productivity, and this was because of the fact that the constantly deepened capital caused the constant decrease in the labor quantity absorbed by unit capital, and finally resulted in tourism investment rejecting labor employment, and this was reflected in the contribution to tourism economic growth, and the contribution rate of capital factor for tourism economic growth was largely higher than the contribution rate of labor factor [5].

TABLE III The Growth RATE OF TOURISM INPUTS AND ITS CONTRIBUTION TO THE TOURISM OUtPUT IN CHINA (1996-2015)

\begin{tabular}{|c|c|c|c|c|c|c|c|}
\hline \multirow{2}{*}{ Year } & \multirow{2}{*}{$\begin{array}{l}\text { Growth Rate of } \\
\text { Tourism } \\
\text { Incomes }\end{array}$} & \multicolumn{3}{|c|}{ Growth Rate of Factors } & \multicolumn{3}{|c|}{$\begin{array}{l}\text { Contribution of Factors for Economic } \\
\text { Growth }\end{array}$} \\
\hline & & Capital & Labor & TFP & Capital & Labor & TFP \\
\hline 1996 & 0.3153 & 0.1675 & 0.0725 & 0.1770 & 0.3624 & 0.0732 & 0.5615 \\
\hline 1997 & 0.1178 & 0.3751 & 0.1359 & -0.1024 & 2.1717 & 0.3670 & -0.8694 \\
\hline 1998 & 0.1032 & 0.2076 & 0.3462 & -0.0318 & 1.3715 & 1.0664 & -0.3080 \\
\hline 1999 & 0.1339 & 0.1081 & 0.0628 & 0.0547 & 0.5508 & 0.1491 & 0.4082 \\
\hline 2000 & 0.2110 & 0.2517 & 0.0697 & 0.0353 & 0.8136 & 0.1051 & 0.1672 \\
\hline 2001 & -0.0266 & -0.0569 & -0.0356 & 0.0136 & 1.4603 & 0.4259 & -0.5127 \\
\hline 2002 & 0.1612 & 0.1924 & 0.0912 & 0.0270 & 0.8138 & 0.1799 & 0.1675 \\
\hline 2003 & -0.033 & 0.0856 & 0.0812 & -0.0575 & $3^{-17.531}$ & -7.7572 & 17.2869 \\
\hline 2004 & 00.0980 & 0.0854 & 0.0103 & 0.0365 & 0.5945 & 0.0335 & 0.3723 \\
\hline 2005 & 0.1753 & 0.2957 & 0.0635 & -0.0180 & 1.1505 & 0.1152 & -0.1028 \\
\hline 2006 & 0.0619 & 0.1269 & 0.0419 & -0.0223 & 1.3997 & 0.2155 & -0.3613 \\
\hline 2007 & 0.1303 & 0.0618 & 0.0026 & 0.0825 & 0.3237 & 0.0064 & 0.6334 \\
\hline 2008 & -0.0161 & 0.0778 & 0.0003 & -0.0648 & -3.2959 & -0.0061 & 4.0271 \\
\hline
\end{tabular}




\begin{tabular}{|c|c|c|c|c|c|c|c|}
\hline \multicolumn{9}{|c|}{ Table III, cont } \\
\hline 2009 & 0.0685 & 0.0161 & 0.0103 & 0.0556 & 0.1606 & 0.0477 & 0.8120 \\
\hline 2010 & 0.1209 & 0.0381 & 0.0102 & 0.0904 & 0.2150 & 0.0269 & 0.7477 \\
\hline 2011 & 0.0446 & 0.1197 & 0.0263 & -0.0337 & 1.8309 & 0.1878 & -0.7558 \\
\hline 2012 & 0.0875 & 0.0436 & 0.0529 & 0.0547 & 0.3400 & 0.1922 & 0.6250 \\
\hline 2013 & 0.0260 & 0.0087 & -0.0200 & 0.0195 & 0.2269 & -0.2446 & 0.7507 \\
\hline 2014 & 0.0488 & 0.0047 & -0.0693 & 0.0446 & 0.0651 & -0.4510 & 0.9136 \\
\hline 2015 & 0.04 & 0.0050 & 0.0622 & 0.0357 & 0.0852 & 0.4944 & 0.8934 \\
\hline Average & 0.0949 & 0.1107 & 0.0508 & 0.0198 & 0.6201 & 0.1710 & 0.2089 \\
\hline
\end{tabular}

V. CONCLUSION AND POLICY SUGGESTIONS

The research result has showed that: (1) from 1995 to 2015, the overall level for the growth of total factor productivity in Chinese tourism was low, and the average growth rate was merely $1.98 \%$, and the growth of total factor productivity growth rate is closely related to the fluctuation of tourism economy, and the capital growth must be matched with the productivity, so as to bring high economic growth, and excessive capital inputs will decrease total factor productivity on the contrary and then influence the growth of output in the tourism industry. (2) From 1995 to 2015, the tourism economy in our country belongs to typical factor-driven intensive growth mode, of which the contribution of capital factors for tourism output growth reached to $62.01 \%$; the contribution of labor factors for tourism output growth was $17.1 \%$, and the total contribution of production factors reached up to $79.11 \%$, and the contribution of total factor productivity for tourism output was merely $20.89 \%$, and it can be seen that the economic growth in our country mainly relies on the drive of production factors (mainly capital factors), rather than being realized through technical progress and innovation, and it is a low-quality growth. (3) The deepening of tourism capital has caused the development of tourism economy towards the direction of capital replacing labor force; on one hand, this has restricted the positive effect of labor productivity growth on tourism economic growth; on the other hand, the deepening of capital has caused the sharp decrease in investment efficiency and then influence the tourism output growth.

The tourism economic growth not only comes from the increase in production factor input, but also relies on the improvement of production efficiency. Through factor input, the tourism industry in our country has realized the expansion of tourism economy quantity, and in the future, it is requested to pay more attentions to the improvement of economic growth quality [6]. The suggestion for future tourism economic development policy is to: (1) enlarge the establishment of valid incentive mechanism and innovation assurance mechanism, improve the tourism enterprise innovation capacity as well as the management efficiency of personnel, properties and objects, and improve the industrial technology progress rate; (2) conduct the structural adjustment of tourism industry, ensure the transfer of production factors towards departments or projects with higher efficiency, so as to realize the improvement of capital productivity for the tourism industry; (3) promote the structural upgrading of tourism industry, and improve the contribution rate of scientific and technological progress for tourism economic growth.

\section{ACKNOWLEDGMENT}

About the Author: Wu Linping (1976- ), female, born in Xianyou, Fujian, the Lecturer and Master of Tourism Department in Minjiang University; Research Direction: Tourism Management.

Fund Project: Young and Middle-aged Project of the Education Department of Fujian "Carbon Emission, Green Total Factor Productivity and Tourism Economic Growth" (Project No.: JAS170361)

\section{REFERENCES}

[1] Li Ping and Zhong Xueyi.Chinese Productivity Changes and Economic Growth Fountain: 1978-2010 [J]. Quantitative \& Technical Economics, 2013, (1):3-21. (In Chinese)

[2] Zuo Bing and Bao Jigang. Total Factor Productivity and Interprovincial Difference of Chinese Tourism Industry from 1992 to 2005 [J]. Journal of Geographical Sciences, 2008, 63(4):417-427. (In Chinese)

[3] Zuo Bing. Analysis on the Tourism Economic Growth Factors and the Contribution Degree in China $[\mathrm{J}]$;Business Economics and Administration, 2011,(10):8-88.(In Chinese)

[4] Duan Wenbin and Yin Xiangfei, Research Review about Chinese Total Factor Productivity [J]. Nankai Economic Studies, 2009, (2):130-140. (In Chinese)

[5] Wu Linping. Estimation about the Total Factor Productivity of Chinese Tourism Industry [J]; Statistics and Decision, 2017, (09):135-139. (In Chinese)

[6] Wei Jie, Ren Baoping. Theoretical and Empirical Analysis on the Factor Productivity and Economic Growth Quality-Based on the Data of 1952-2007 [J]. Journal of SUEE,2009,30(10): 82-88.(In Chinese)

[7] China National Tourism Administration. Tourism Statistical Yearbook (Copy),Beijing: China Travel \& Tourism Press, 1996-2016.(In Chinese)

[8] National Bureau of Statistics of China. China Statistical Yearbook, Beijing: China Statistics Press, 1996-2016.(In Chinese) 